\title{
Effect of Long Aerobic Exercise on Bone Mineral Density in Elderly Patients with Osteoporosis
}

\author{
Qiang Liu, Longling Xiao \\ School of Physical Education, Wenshan University, Wenshan 663099, China
}

1124286@qq.com

Keywords: Different length, aerobic exercise, osteoporosis, bone mineral density

\begin{abstract}
Purpose: Inquiry is not the same effect on the long aerobic exercise on bone mineral density in elderly patients with osteoporosis. Methods January 2013-January 2014 in our hospital 120 cases of senile osteoporosis patients in this study, according to the motion duration were divided into control group and observation group and control group patients three times a week aerobic sports, the observation group were 3-5 times per week of aerobic exercise, changes in bone mineral density were compared. Result: After treatment, the observation group hip bone mineral density $(0.68 \pm 0.12) \mathrm{g} / \mathrm{cm} 2$, lumbar spine bone mineral density $(0.91 \pm 0.20) \mathrm{g} / \mathrm{cm} 2$, significantly better than the control group $(0.62 \pm 0.12) \mathrm{g} / \mathrm{cm} 2,(0.84 \pm 0.10) \mathrm{g} / \mathrm{cm} 2$, the difference was significant $(\mathrm{P}$ $<0.05)$. BGP for the observation group after treatment $(5.78 \pm 0.42) \mu \mathrm{g} / \mathrm{L}, \mathrm{U}-\mathrm{Pyd} / \mathrm{Cr}(36.9 \pm 3.2) /$ mmol, was significantly better than the control group BGP was $(1.94 \pm 0.32) \mu \mathrm{g} / \mathrm{L}$, $\mathrm{U}-\mathrm{Pyd} / \mathrm{Cr}(30.1 \pm 2.4) / \mathrm{mmol}$, the difference was statistically significant $(\mathrm{P}<0.05)$. In conclusion: Aerobic exercise 3-5 times a week, every $0.5-1 \mathrm{~h}$, can effectively improve elderly patients with osteoporosis bone density, while promoting bone formation and bone resorption, prevention of osteoporotic fractures have significant effects.
\end{abstract}

For patients with the three principles of prevention of osteoporosis include: calcium, dietary modification, exercise, exercise is one in which the most basic prevention and treatment of osteoporosis is the most effective method. Through exercise can effectively regulate blood circulation and neurohumoral regulation regulation, while effectively increasing the flexibility and coordination body of the patient, reducing the chance of injury and fall[1-2]. Effective exercise can be effective in the blood calcium transport osteoclast formation of osteoblasts [3]; on this basis, can promote intestinal absorption of patients, improve the absorption of nutrients, especially calcium ion absorption. Our hospital is often explore different sports on the prevention and treatment of senile osteoporosis occurs, the two groups of patients taking a different time and frequency of aerobic exercise, the results reported below.

\section{Materials and Methods}

General Information Act. Select January 2013-January 2014 in our hospital 120 cases of senile osteoporosis patients in this study, according to the different recovery methods were divided into control group and observation group,60 cases in each; all patients were selected to meet WHO diagnostic clinical criteria of osteoporosis[2]:patients peak BMD 2.5 standard deviations below the same sex (T-score<-2.5).The control group 24 males and 36 females; age 63-78 years, mean age (68.4 \pm 3.7$)$ years; weight 56-72kg, average $(62.3 \pm 4.1) \mathrm{kg}$. Observation group 25 males and 35 females; aged 61-79 years, mean age (68.0 \pm 3.9$)$ years; weight $55-74 \mathrm{~kg}$, average $(62.0 \pm 4.5) \mathrm{kg}$. Two groups in gender, age, weight Comparison $\mathrm{P}>0.05$, the difference was not statistically significant. 
Methods. Aerobic exercise is a long time, rhythm, exercise is not intense, big muscles, comprising: jogging, brisk walking, hiking, dancing, tai chi, cycling, patients in both groups according to their own circumstances, habits, weather and so the appropriate choice of their own aerobic exercise. Patients in the control group three times a week for aerobic exercise, each exercise control in time $0.5 \mathrm{~h}$; the observation group were 3-5 times a week for aerobic exercise, each exercise time control 0.5-1h; All patients adheremotion 3 months, and recorded in the patient's condition changes after 3 months.

Outcome Measures. Comparison of two groups of patients before and after the change of bone mineral density, while at the end of treatment on bone metabolism in two groups of patients were recorded, including indexes of bone formation (BGP) and bone resorption index (U-Pyd/Cr)[3].

Statistical. The study used SPSS18.0 statistical software for data processing, which count data $\mathrm{n}$ (\%) that the use of $\chi^{2}$ test; measurement data $(\chi \pm s)$ said, using $\mathrm{t}$ test, the results of $\mathrm{P}<0.05$ representing the difference between statistically significant.

\section{Results}

The two changes in bone mineral density in patients before and after comparison. After treatment, the observation group hip bone mineral density $(0.68 \pm 0.12) \mathrm{g} / \mathrm{cm} 2$, lumbar spine bone mineral density $(0.91 \pm 0.20) \mathrm{g} / \mathrm{cm} 2$, significantly better than the control group $(0.62 \pm 0.12) \mathrm{g} / \mathrm{cm} 2$, $(0.84 \pm 0.10) \mathrm{g} / \mathrm{cm} 2$, the difference was significant $(\mathrm{P}<0.05)$. Table 1.

Table 1 changes of bone mineral density in two groups of patients before and after treatment comparison $\left(\chi \pm \mathrm{s} ; \mathrm{g} / \mathrm{cm}^{2}\right)$

\begin{tabular}{cccccc}
\hline \multirow{2}{*}{ Group } & \multirow{2}{*}{$\begin{array}{c}\text { Number } \\
\text { of cases }\end{array}$} & $\begin{array}{c}\text { Before } \\
\text { treatment }\end{array}$ & $\begin{array}{c}\text { After } \\
\text { treatment }\end{array}$ & $\begin{array}{c}\text { Before } \\
\text { treatment }\end{array}$ & $\begin{array}{c}\text { After } \\
\text { treatment }\end{array}$ \\
\hline Group & 60 & $0.61 \pm 0.11$ & $0.62 \pm 0.12$ & $0.78 \pm 0.13$ & $0.84 \pm 0.10$ \\
Observer Group & 60 & $0.61 \pm 0.10$ & $0.68 \pm 0.12$ & $0.80 \pm 0.11$ & $0.91 \pm 0.20$ \\
$\mathrm{t}$ & & 0.000 & 2.738 & 0.909 & 2.424 \\
$\mathrm{P}$ & & 1.000 & 0.007 & 0.364 & 0.016 \\
\hline
\end{tabular}

Two groups of patients before and after treatment changes in bone metabolism indicators, as shown in Table 2. BGP for the observation group after treatment $(5.78 \pm 0.42) \mu \mathrm{g} / \mathrm{L}$, U-Pyd/Cr $(36.9 \pm 3.2) / \mathrm{mmol}$, was significantly better than the control group BGP was $(1.94 \pm 0.32) \mu \mathrm{g} / \mathrm{L}$, $\mathrm{U}-\mathrm{Pyd} / \mathrm{Cr}(30.1 \pm 2.4) / \mathrm{mmol}$, the difference was statistically significant $(\mathrm{P}<0.05)$. 
Table 2 two groups of patients before and after treatment changes in bone metabolism $(\chi \pm \mathrm{s} ; \mu \mathrm{g} / \mathrm{L} ; \mathrm{nmol} / \mathrm{mmol})$

\begin{tabular}{cccccc}
\hline \multirow{2}{*}{ Group } & \multirow{2}{*}{$\begin{array}{c}\text { Number of } \\
\text { cases }\end{array}$} & $\begin{array}{c}\text { Before } \\
\text { treatment }\end{array}$ & $\begin{array}{c}\text { After } \\
\text { treatment }\end{array}$ & $\begin{array}{c}\text { Before } \\
\text { treatment }\end{array}$ & $\begin{array}{c}\text { After } \\
\text { treatment }\end{array}$ \\
\cline { 3 - 6 } Group & 60 & $1.79 \pm 0.23$ & $1.94 \pm 0.32$ & $38.2 \pm 3.9$ & $30.1 \pm 2.4$ \\
Observer Group & 60 & $1.81 \pm 0.21$ & $5.78 \pm 0.42$ & $37.8 \pm 4.1$ & $36.9 \pm 3.2$ \\
$\mathrm{t}$ & & 0.497 & 56.332 & 0.547 & 13.16 \\
$\mathrm{P}$ & 0.619 & 0.000 & 0.585 & 0.000 \\
\hline
\end{tabular}

\section{Discussion}

Osteoporosis is a common disease worldwide, often easily overlooked until fracture occurs by the phenomenon, only to find changes in bone mineral density and bone mass has occurred [4-5], since that is not timely, the bone fractures caused by osteoporosis have a serious impact on health and quality of life of older persons. For the treatment of the disease is often treated conservatively, that fixation combined with oral anti-osteoporosis drug treatment modalities [6]. The principle of anti-osteoporosis treatment drugs are mainly three types: the first is to inhibit the formation of osteoclasts, such osteoclasts reduced ability to reduce the loss of bone mass; the second is to enhance the vitality of bone cells and promote the formation of bone; $s$ third is to promote bone mineral precipitation, and ultimately to improve bone density and quality of purpose [7-8]. Thus, anti-osteoporosis drugs are divided into three categories: bone resorption suppressing drugs, drugs to promote bone formation and bone mineralization promote drug.

Want bone generating the adaptive response must be to stimulate the duration of a certain length, bone reconstruction cycle usually takes 3-4 months, change in bone mass at the same time to reach a new level of stability is required 7-9 months [9], and over that period of exercise is more significant for increasing bone mass. Related research indicates[5], want to pass a certain exercise time impact on bone density, time cannot be less than four weeks, through five months of weight training can improve upper limb bone mineral density of the distal radius content. Norway, one study [10], the time is not less than weekly sports 3h, femur and lumbar spine bone mineral density in women of content in order to increase significantly. The study group patients were observed aerobic exercise 3-5 times a week, each time motion control in $0.5-1 \mathrm{~h}$, and adhere to exercise for three months, while the control group only 3 times per week of aerobic exercise, every time $0.5 \mathrm{~h}, 3$ months after the discovery observation group were hip and lumbar spine bone mineral density was significantly higher $(\mathrm{P}<0.05)$, and indexes of bone formation and resorption index was also significantly higher $(\mathrm{P}<0.05)$, the difference was statistically significant.

In summary, through the appropriate length of aerobic exercise can effectively improve the patient's bone density at the same time within a certain range, the longer the time of patient motion, the higher the frequency the greater the stimulation of bone stress can effectively maintain and improve bone density levels. But each exercise time not too long, and the frequency cannot be too large, or have a negative effect. If you want to improve bone density must let the patient movement lasted more than three months, once the stop motion in patients with bone minerals can significantly reduce, or even lower than the original level, so exercise to increase bone mineral density the effect is reversible, but the movement must persevere. 


\section{References}

[1] Qiaoge Chen,Ying Jin,Jingjing Zhu.etc. Journal of Nurses Training, 2013,28(19):1776-1778.

[2] Fei Qin,Xinlei Zhang,Yang Ruan.etc. Journal of Physical Education, 2013,(6):126-131.

[3] Yali Chen,Lianxin Song. Chinese Journal of Gerontology,2012,32(22):4972-4974.

[4] Yunming Wu, Xiaobo Hao, Xicheng Wang.etc. Chinese Journal of Gerontology, 2014,(14):4113-4115.

[5] Qian Shi,Yujia Yang,Li Gao.etc. Chinese Journal of Nursing, 2013,48(4):331-334.

[6] Wormald PJ.The agger nasi cell: the key to understanding the anatomy of the frontal recess. Otolaryngol Head Neck Surg. 2011, 129: 497-507.

[7] CHOI BI, LEE HJ, H AN JK, et al. AJR,2010,157(2):219-224

[8] KHANMA,COM BS CS, BRUNT EM, et al. Ann Nucl Med,2009,14(2):121-126

[9] Tabit CE,Chung WB,Hamburg NMet al. Rev Endocr Metab Disord,2010,11(1):61-74.

[10] Endemann DH,Schiffrin EL. Endothelial dysfunction. J Am Soc Nephrol,2010,15(8):19831992. 